\title{
Tolerability of Eribulin and Correlation Between Polymorphisms and Neuropathy in an Unselected Population of Female Patients with Metastatic Breast Cancer: Results of The Multicenter, Single Arm, Phase IV PAINTER Study
}

\section{NICLA LA VERDE}

Department of Oncology, Luigi Sacco Hospital, ASST Fatebenefratelli Sacco. Milan

\section{GIOVANNA DAMIA}

Laboratory of Molecular Pharmacology, Istituto di Ricerche Farmacologiche Mario Negri IRCCS, Milan ORNELLA GARRONE

Medical Oncology, Fondazione IRCCS Ca' Granda Ospedale Maggiore Policlinico, Milan

\section{DANIELE SANTINI}

Oncologia Medica, Università Campus Biomedico, Roma

\section{ALESSANDRA FABI}

Fondazione Policlinico Universitario A. Gemelli, IRCCS, Roma

\section{MARIANGELA CICCARESE}

Dept of Oncology Vito Fazzi Hospital, Lecce

\section{DANIELE GIULIO GENERALI}

U.O. Multidisciplinare di Patologia Mammaria e Ricerca Traslazionale Azienda Socio-Sanitaria

Territoriale di Cremona

\section{MARTINA NUNZI}

Dept. of Oncology Medical and Translational Oncology Unit, Azienda Ospedaliera S.Maria, Terni

\section{ELENA POLETTO}

ASUFC Presidio Ospedaliero Universitario S.M. Misericordia, Udine

\section{ELISA FERRARIS}

Division of Medical Oncology, IRCCS San Matteo University Hospital Foundation, Pavia

\section{ELISABETTA CRETELLA}

Oncologia Medica Ospedale di Bolzano, AS Alto Adige, Bolzano

\section{GIUSEPPA SCANDURRA}

Oncologia Medica Ospedale per le Emergenze Cannizzaro, Catania

\section{ICRO MEATTINI}

Radiation Oncology Unit, Oncology Department, Azienda Ospedaliero Universitaria Careggi, Florence 
SOC Oncologia Medica- ASST della Valtellina e Alto Lario, Sondrio

\section{LUIGI CAVANNA}

Oncology Haematology Department, ASL Piacenza

\section{ELENA COLLOVA'}

ASST Ovest Milanese, Ospedale di Legnano, Legnano (MI)

\section{EMANUELA ROMAGNOLI}

UOC Oncologia, Ospedale Macerata, Macerata it

\section{ELIANA RULLI}

Laboratory of Methodology for Clinical Research, Istituto di Ricerche Farmacologiche Mario Negri IRCCS, Milan

\section{LORENZO LEGRAMANDI}

Laboratory of Methodology for Clinical Research, Istituto di Ricerche Farmacologiche Mario Negri IRCCS, Milan

\section{FEDERICA GUFFANTI}

Laboratory of Molecular Pharmacology, Istituto di Ricerche Farmacologiche Mario Negri IRCCS, Milan

\section{ANNALISA BRAMATI}

Department of Oncology, Fatebenefratelli Hospital, ASST Fatebenefratelli Sacco. Milan

\section{ANNA MORETTI ( $\nabla$ anna.moretti@asst-fbf-sacco.it )}

Department of Oncology, Fatebenefratelli Hospital, ASST Fatebenefratelli Sacco. Milan

\section{ALESSANDRA CASSANO}

Oncologia Medica, Università Cattolica del Sacro Cuore, Fondazione Universitaria Policlinico A. Gemelli IRCCS, Roma

\section{PATRIZIA VICI}

Department of Phase IV Clinical Trials, IRCCS Regina Elena National Cancer Institute, Rome, Italy

\section{VALTER TORRI}

Department of Phase IV Clinical Trials, IRCCS Regina Elena National Cancer Institute, Rome, Italy

\section{GABRIELLA FARINA}

Department of Oncology, Fatebenefratelli Hospital, ASST Fatebenefratelli Sacco. Milan

\section{Research Article}

Keywords: breast cancer, eribulin, neurotoxicity, polymorphisms, peripheral neuropathy

Posted Date: February 7th, 2022

DOI: https://doi.org/10.21203/rs.3.rs-1321818/v1

License: (c) (1) This work is licensed under a Creative Commons Attribution 4.0 International License. Read Full License 


\section{Abstract}

\section{BACKGROUND}

Metastatic breast cancer (MBC) is an incurable disease and its treatment focuses on prolonging patients (pts) overall survival (OS) and improving their quality of life. eribulin is a microtubule inhibitor that increases OS in pre-treated MBC pts. Its common adverse events (AEs) are asthenia, neutropenia and peripheral neuropathy (PN).

\section{METHODS}

The PAINTER is a single arm, phase IV study, aimed at surveying eribulin tolerability in MBC pts. Secondary objectives were to explore incidence and severity of PN, its association with genetic polymorphisms, and the description of treatment efficacy and safety. Genomic DNA was isolated from blood samples and 15 Single Nucleotide Polymorphisms (SNPs) were genotyped by Taqman specific assays. The associations between PN and SNPs were evaluated by Fisher exact test.

\section{RESULTS}

From May 2014 to June 2018180 pts were enrolled from 20 Italian centers; 170 were evaluable for efficacy and toxicity and 159 for polymorphisms analysis. Median age was 60 years, biological subtypes were luminal type (64.7\%), Her2 positive (18.3\%) and triple negative (17\%). Pts were pretreated with a median of 5 lines for MBC. With a median follow up of 15.4 months, a median number of eribulin cycles of 4.5 (minimum-maximum 1-23), median overall survival was 12 months. $48.8 \%$ of pts experienced dose reduction, mainly for neutropenia (23.9\%) and liver injury (12\%). 65 pts (38.2\%) reported at least one severe toxicity. Neutropenia and neurotoxicity were the most frequent severe AEs ( $15.3 \%$ and $14.7 \%$ respectively); other toxicities were osteo-muscular, abdominal or tumor site pain (19.4\%), liver injury (6.6\%), pulmonary toxicity (6.5\%) and dermatological (3.6\%), Among the 15 evaluated SNPs, an association with PN was found for rs2233335 and rs7214723.

\section{CONCLUSIONS}

Eribulin is a well-tolerated treatment in MBC. Schedule and dosage modifications were common, but toxicity rarely led to treatment discontinuation. SNPs rs2233335 (G/T and T/T) in NDRG1 gene and rs7214723 (CC and CT) in CAMKK1 gene were associated with PN. These findings, if validated, could allow a tailored eribulin treatment in cancer patients.

Trial registration: ClinicalTrials.gov ID: NCT02864030

\section{EudraCT: 2013-004600-19}

\section{Background}


Metastatic breast cancer is an incurable disease, with a median survival ranging from 24 to 48 months, variable according to biological characteristics, metastatic sites, patients' age, etc. [1, 2]. Treatments are tailored based patients and tumor characteristics, and the use of new drugs, as CDK4/6 inhibitors or monoclonal antibodies significantly improved disease control [3, 4]. Although the development of new agents, single-agent chemotherapy remains an important backbone in the metastatic setting.

Capecitabine, vinorelbine and eribulin are the preferred treatment options after anthracycline and taxanes chemotherapy [2].

Eribulin is a synthetic analogue of the natural product halichondrin B. Its cytotoxic effects are mainly due to its ability to interfere with microtubule dynamic, causing blockage of mitotic spindle formation, mitotic arrest and cell death by apoptosis [5]. Differently from other microtubule interfering agents, eribulin inhibits the growth phase of the microtubule without any inhibition of the shortening phase [6-8]. However, many other non-mitotic effects of eribulin on tumor biology have been described, including tumor vascular remodeling, leading to better tumor perfusion and reduced hypoxia, and interference with epithelial mesenchymal transition reducing tumor cell ability to migrate and invade, both in vitro and in vivo. These latter eribulin effects seem to be important to justify the observed drug clinical activity [9].

Eribulin has been approved by the Food and Drug Administration in 2010 and in Italy in 2012 for the treatment of patients with locally advanced or metastatic breast cancer in progression after at least one chemotherapy regimen, consisting of anthracycline and taxanes in both adjuvant and metastatic settings.

The approval in breast cancer was based on the results of two randomized phase III trials [10, 11]. The first trial EMBRACE [10] enrolled 762 women with locally recurrent or MBC randomly assigned (2:1) to eribulin or treatment of physician's choice (TPC). Overall survival was significantly improved in the experimental arm (median 13.1 months, 95\% Cl 11.8-14.3) compared to TPC arm (10.6 months, 9.3-12.5; hazard ratio $0.81,95 \% \mathrm{Cl} 0.66-0.99 ; \mathrm{p}=0.041$ ). The second trial, the 301 study [11], evaluated the efficacy and safety of eribulin as first, second or third line monotherapy versus capecitabine in 1102 patients with locally advanced breast cancer or MBC previously treated with anthracyclines and taxanes. The median OS was 15.9 months for eribulin versus 14.5 months for capecitabine (HR 0.879; 95\% Cl: 0.770-1.003; $p=0.056)$, failing in demonstrating a superiority of eribulin. A pooled analysis suggested a major benefit in the subgroup of women with HER2 negative disease [12]. Results from phase III trials suggested that eribulin treatment was well tolerated and the most common adverse effects (AEs) were neutropenia, fatigue and peripheral neuropathy. Specifically, this latter AE occurred in $5 \%$ of patients of the EMBRACE study and in $13 \%$ of the patients enrolled in the 301 study. In a recent meta-analysis, the incidences of allgrade and high-grade peripheral neuropathy after Eribulin treatment were $27.5 \%$ (95\% Cl: $23.3-32.4 \%$ ) and 4.7\% (95\% Cl: 3.6-6.2\%), respectively [13]. Although the precise mechanism of neurotoxicity associated with microtubule interfering agents (taxanes, vinca alkaloids and eribulin) have not fully defined yet, preclinical and histological studies suggest that its pathogenesis is mainly a consequence of the interruption of the axon transport within the neuron, that relies on intact microtubule structures [14, 15]. The prevalence of severe neuropathy is extremely variable, suggesting that individual characteristics 
might affect susceptibility. For this reason, the study of gene polymorphism could help in identifying patients at higher risk of developing neurotoxicity, as demonstrated for taxanes. [14; 16]

We here report the results of PAINTER study that aimed at evaluating the toxicity and quality of life (QoL) in unselected Italian patients with MBC treated with eribulin. The correlation between neurotoxicity and SNPs was also explored.

\section{Methods}

\section{Study design and participants}

The PAINTER study is a single arm, phase IV, multicentre study aimed, as primary objective, at surveying the tolerability profile of eribulin in an unselected population of patients with MBC (real life setting). The secondary objectives are the study of the relationship between specific genetic polymorphism and incidence and severity of peripheral neuropathy and the description of treatment efficacy in terms of duration of treatment and survival.

Study population included patients diagnosed with MBC treated with eribulin as for Italian regulatory indications.

All patients received intravenous infusion of $1.23 \mathrm{mg} / \mathrm{m}^{2}$ eribulin mesylate on days 1 and 8 on a 21-day cycle. Cycles were repeated until progression of disease, unacceptable toxicity, patient refusal or medical decision. The physician could choose any further line of treatment after disease progression. Patients were monitored in order to identify any AE during eribulin treatment and up to 30 days after its discontinuation. Follow-up visits for survival assessment were performed every 4 months.

QoL was evaluated on day 1 of every cycle, and 30 days after the discontinuation of study treatment using EORTC QLQ-C30 and QLQ-BR23 questionnaires.

The study complied with the Declaration of Helsinki, was performed according to Good Clinical Practice guidelines and was approved by the local ethic committees in all the participating centers. All patients provided written informed consent. The study protocol is registered with ClinicalTrials.gov NCT0286403.

\section{Endpoints}

The study endpoints were:

- incidence, time of onset, severity and duration of all AEs experienced during treatment with eribulin, especially the most common reported in previous studies (asthenia/fatigue, neutropenia, peripheral neurotoxicity, constipation alopecia, nausea), but also other possible unexpected toxicities. The primary analysis was based on severe AE (SAEs) defined as grade 3 or 4 AEs, except for neuropathy and alopecia for which a grade 2 was considered severe; 
- assessment of dose intensity and dose schedule maintenance as indirect index of tolerability;

- Duration of treatment (DOT) and Overall Survival (OS).

- evaluation of QoL during treatment, using validated questionnaires;

- association between a set of selected SNPs and the occurrence of any grade peripheral neuropathy. Specifically, 15 SNPs located in genes involved in microtubule dynamics or resulted from genome wide association studies, were analyzed.

\section{Sample size}

The planned sample size was 200 patients, based on temporal and logistic constraints.

For the purpose of the estimation, the severe toxicity (Grade 3 or 4 ) has been chosen as a safety endpoint of primary interest. A sample size of 200 patients, considering a toxicity rate between 20 and $40 \%$, produces a $95 \%$ confidence interval $(95 \% \mathrm{Cl})$ with amplitude of at most $14 \%$, deemed sufficiently precise to draw valid conclusions around the event rate. The estimation of the $95 \% \mathrm{Cl}$ was based on ClopperPearson methodology [17]. Moreover, a sample size of 200 patients allowed to get a good fitting for statistical analysis of relationship between primary endpoint and not more than 10 factors [18] and to study the relationship between 10-15 polymorphisms, with a known prevalence $>15 \%$, and risk of neuropathy. Assuming a risk of neuropathy of $30 \%$, and a clinically relevant association in terms of odds ratio (OR) of 3 , the study had $80 \%$ power to detect a statistically significant association at $2.5 \%$ one side level for each assessment.

\section{Statistical methods}

Eribulin safety was analyzed on the "safety patients set", including patients who received at least one dose of treatment. For those patients included in the safety set whose blood samples were available, the evaluation of polymorphisms was performed ("molecular analysis patients set"). AEs were described using the maximum grade observed during the treatment. The SAEs were described by means of absolute and relative frequencies and associated $95 \% \mathrm{Cl}$ estimated by means of exact binomial methods. The occurrence of neuropathy was described using the cumulative incidences of any grade and severe grade (equal or greater than grade 2) by means of Kaplan-Meier methods.

The relationship between polymorphisms and risk of neuropathy was described by contingency tables and their association was assessed by $\chi 2$ test for trend and a Fisher exact test in order to detect one of two different pathways of association, linear or dominant model. For those polymorphisms that resulted associated to neuropathy with the previous tests, the association with severe (G2-3-4) neuropathy was assessed by a univariable logistic model. No multivariable model was planned for the low number of severe neuropathy events. 
DOT was calculated as the time from start of eribulin treatment to its discontinuation. OS was calculated as the time from treatment start to the date of death from any cause. Patients alive at the end of the study were censored at the last date they were known to be alive. DOT and OS were described using Kaplan-Meier curves. The cumulative incidences for the two competitive events of interest (toxicity and progression) were calculated for DOT analysis according to the Fine and Grey's method.

QoL scores at 3 months and at the end of treatment were compared with baseline scores for each patient separately for each questionnaire scale. A paired T-test was used to analyze changes. A p value $<0.05$ was considered as statistically significant. The analysis was exploratory in nature and for this reason no adjustment for multiple assessment was planned. All analyses were performed using SAS Version 9.4.

\section{SNPs analysis}

For the determination of polymorphisms, blood was collected in a Vacutainer containing EDTA any time during the participant's first two treatment cycles and stored at $-20^{\circ}$ Celsius until further processing. Genomic DNA was purified from whole blood samples using the Maxwell ${ }^{\circledR}$ RSC Whole Blood DNA kit (Promega, Italy). DNA was amplified using the TaqMan ${ }^{\circledR}$ Genotyping Master Mix (Thermo Fisher Scientific, USA) and analyzed according to manufacturer's instructions for the presence of selected SNP allele variants by real-time PCR technique (ABI-7900; Applied Biosystems, Italy) using TaqMan SNP Genotyping assays (Thermo Fisher Scientific, USA) specific for each gene of interest. Supplementary Table 1 shows the SNPs analyzed, selected based on their reported association with anticancer agents induced neuropathy. Real-time PCR were carried out in 384-wells plates prepared with automatic liquid handling (epMotion 5075; Eppendorf, Italy). Completed PCR plates were analyzed using the TaqMan ${ }^{\circledR}$ Genotyper Software (Thermo Fisher Scientific, USA).

\section{Results}

From May 2014 to June 2018, 180 pts were enrolled from 20 different Italian centers. As depicted in Flow chart (Figure 1), 10 patients were excluded from the safety analysis: 2 patients due to major protocol violations (having received eribulin in previous lines of treatment), 8 patients because they never started eribulin treatment. Only 159 patients out of 180 were included in the analysis of polymorphisms (molecular analysis set), as for 11 patients there were no available blood samples. Ninety-eight patients (54.4\%) were considered for QoL assessment. The median of follow-up was 15.4 months.

The main baseline characteristics, according to the analysis sets, are summarized in Table 1. Overall, mean patient age was 59.7, $64 \%$ had a Luminal B HER-2 negative metastatic breast cancer, ECOG Performance status was $0-1$ in $100 \%$ of the patients, and the mean number of previous chemotherapy lines for metastatic disease was 5 (from 0 to a maximum of 18). Previous neuropathy was reported in $15.9 \%$ and $17 \%$ of patients in the safety and molecular analysis sets, respectively.

The median number of eribulin cycles administered per patient was 4.5 (first quartile[Q1]- third quartile[Q3] 3.0-7.0) from a minimum of 1 to a maximum of 23 cycles. Half of patients received $84.7 \%$ of 
the cycles at the full dose and for 83 patients $(48.8 \%)$ the treatment was modified, mostly before the $3^{\text {rd }}$ cycle. The main reasons for treatment discontinuation were disease progression (82.9\%), lost to follow up (4.7\%), medical decision (4.7\%) and toxicity (3.5\%). 
Table 1. Demographic and Baseline Characteristics

Molecular analysis set

$\mathrm{N}=159$

Age

Mean (SD)

Median (Q1-Q3)

BMI $\left(\mathrm{Kg} / \mathrm{m}^{2}\right)$

Mean (SD)

Median (Q1-Q3)

Time from diagnosis (years)

Mean (SD)

Median (Q1-Q3)

Histology - n (\%)

Ductal

Lobular

Unknown/missing

Biological subtype $n$ (\%)

HER2 positive

Luminal

Triple Negative

Missing

Metastasis - n (\%)

Not visceral

Visceral

Number of therapy lines in metastatic setting - $\mathbf{n}(\%)$

Mean (SD)

$5.0(3.1)$

$5.0(3.0-7.0)$

$3(\%)$

Missing

Baseline neurotoxicity - n (\%)

Median (Q1-Q3)

$50(31.4)$

$109(68.6)$

$26(18.1)$

$15(\%)$
Safety analysis set

$\mathrm{N}=170$

59.7 (12.0)

$60.0(51.0-69.0)$

25.5 (4.9)

24.7 (22.0-28.5)

$7.9(5.8)$

6.1 (3.5-11.0)

129 (86.6)

20 (13.4)

21 (\%)

28 (18.3)

99 (64.7)

26 (17.0)

17 (\%)$$
\text { ) }
$$

117 (68.8)

53 (31.2) 


\begin{tabular}{|lll|}
\hline No & $132(83.0)$ & $143(84.1)$ \\
\hline Yes & $27(17.0)$ & $27(15.9)$ \\
\hline
\end{tabular}

\section{Efficacy}

At a median follow-up of 15.4 months, 94 (55.3\%) patients died, mainly due to disease progression (96.8\%). The median OS was 12 months (Q1-Q3: 6.4-21.7 months) (Figure 2A). The OS was $79.1 \%$ and $49.8 \%$ at 6 and 12 months, respectively. At the time point of the statistical analysis, 8 patients were lost to follow-up and therefore considered as censored for the DOT analysis, while 162 (95.3\%) discontinued the treatment. The median DOT was 3.1 months (Q1-Q3: 1.8-5.1 months) (Figure 2B). Out of 182 patients $145(85.3 \%)$ discontinued for inefficacy, while $17(10 \%)$ for toxicity or patient/medical decision. The cumulative incidence for interruption due to inefficacy was $42.09 \%(95 \% \mathrm{Cl}: 34.50-49.48)$ and $72.28 \%$ (95\% Cl: 64.74-78.48) at 3 and 6 months, respectively. The cumulative incidence for interruption due toxicity was $5.98 \%(95 \% \mathrm{Cl}: 3.05-10.29)$ and $9.00 \%(95 \% \mathrm{Cl}: 5.26-13.97)$ at 3 and 6 months, respectively.

\section{Toxicity}

Table 2 shows the overall incidence of AEs. Overall, 72 (42.4\%) patients experienced at least one severe toxicity. Supplementary Table 2 reports all the recorded adverse events. The most common toxicities occurred were neutropenia (patients with G3-G5: 15.3\%; 95\% Cl 10.2 - 21.6) and neurotoxicity (patients with G2-G5: $14.7 \% ; 95 \% \mathrm{Cl}: 9.75-20.9)$.

The cumulative incidence of toxicities is described in Figure 3 (3A for severe toxicities, 3B for all grade toxicities). The risk of neurotoxicity occurrence in the first 5 cycles was $32.5 \%$ and $13.2 \%$ considering any grade and grades $>1$, respectively. The risk of neutropenia occurrence in the first 5 cycles was $35.9 \%$ and $17.3 \%$ considering any grade and grades $>2$, respectively.

Other G1-G4 toxicities observed were: gastrointestinal in $14.7 \%$ pts, dermatological in $3.6 \%$, liver injury in $6.6 \%$, pulmonary in $6.5 \%$. Interestingly, $19.4 \%$ of pts reported pain, especially osteo-muscular, abdominal and in tumor site. Eleven serious AEs were reported from 10 patients and only two were judged as related to treatment (one febrile neutropenia and jaundice and one hypoesthesia and weakness of the lower limb with fever). 
Table 2. Description of the main adverse events

\begin{tabular}{|c|c|c|c|c|c|c|c|}
\hline Toxicity $N=170$ & $\begin{array}{l}\text { GO } \\
n(\%)\end{array}$ & $\begin{array}{l}G 1 \\
n(\%)\end{array}$ & $\begin{array}{l}\text { G2 } \\
n(\%)\end{array}$ & $\begin{array}{l}\text { G3 } \\
n(\%)\end{array}$ & $\begin{array}{l}\text { G4 } n \\
(\%)\end{array}$ & $\begin{array}{l}\text { G5n } \\
(\%)\end{array}$ & $\begin{array}{l}\text { Severe toxicity } \\
\left(G 3+G 4+G 5^{*}\right) \\
n(\%)[\% 95 \% C l]\end{array}$ \\
\hline $\begin{array}{l}\text { Overall adverse } \\
\text { events }\end{array}$ & $\begin{array}{l}26 \\
(15.3)\end{array}$ & $\begin{array}{l}35 \\
(20.6)\end{array}$ & $\begin{array}{l}58 \\
(34.1)\end{array}$ & $\begin{array}{l}38 \\
(22.4)\end{array}$ & $\begin{array}{l}12 \\
(7.1)\end{array}$ & $1(0.6)$ & $\begin{array}{l}65(38.2)[30.9- \\
46.0]\end{array}$ \\
\hline Neurotoxicity & $\begin{array}{l}114 \\
(67.1)\end{array}$ & $\begin{array}{l}31 \\
(18.2)\end{array}$ & $\begin{array}{l}20 \\
(11.8)\end{array}$ & $5(2.9)$ & $0(0.0)$ & $0(0.0)$ & $\begin{array}{l}25(14.7) \star[9.75- \\
20.9]\end{array}$ \\
\hline Neutropenia & $\begin{array}{l}118 \\
(69.4)\end{array}$ & $\begin{array}{l}15 \\
(8.8)\end{array}$ & $\begin{array}{l}11 \\
(6.5)\end{array}$ & $\begin{array}{l}16 \\
(9.4)\end{array}$ & $\begin{array}{l}10 \\
(5.9)\end{array}$ & $0(0.0)$ & $\begin{array}{l}26(15.3)[10.2- \\
21.6]\end{array}$ \\
\hline Constipation & $\begin{array}{l}145 \\
(85.3)\end{array}$ & $\begin{array}{l}16 \\
(9.4)\end{array}$ & $8(4.7)$ & $1(0.6)$ & $0(0.0)$ & $0(0.0)$ & $\begin{array}{l}1(0.6)[.015- \\
3.23]\end{array}$ \\
\hline Alopecia & $\begin{array}{l}132 \\
(77.6)\end{array}$ & $\begin{array}{l}25 \\
(14.7)\end{array}$ & $\begin{array}{l}13 \\
(7.6)\end{array}$ & $0(0.0)$ & $0(0.0)$ & $0(0.0)$ & $0(0.0)$ \\
\hline Asthenia & $\begin{array}{l}84 \\
(49.4)\end{array}$ & $\begin{array}{l}38 \\
(22.4)\end{array}$ & $\begin{array}{l}38 \\
(22.4)\end{array}$ & $\begin{array}{l}10 \\
(5.9)\end{array}$ & $0(0.0)$ & $0(0.0)$ & $\begin{array}{l}10(5.9)[2.86- \\
10.6]\end{array}$ \\
\hline Nausea & $\begin{array}{l}145 \\
(85.3)\end{array}$ & $\begin{array}{l}19 \\
(11.2)\end{array}$ & $6(3.5)$ & $0(0.0)$ & $0(0.0)$ & $0(0.0)$ & $0(0.0)$ \\
\hline
\end{tabular}

Legend: N: number of subjects; G: Grade; *: G2 was considered as severe toxicity for neurotoxicity

\section{Evaluation of the quality of life}

QoL questionnaires were available for 74 patients $(75.5 \%)$ at the $3^{\text {rd }}$ cycle of eribulin, out of 98 patients with the QoL evaluation at baseline. No differences in global health status and physical, social, emotional, cognitive and role functioning were observed between baseline and $3^{\text {rd }}$ cycle (Supplementary Table 3). Among the 9 reported items/symptoms, a statistically significant worsening was observed only for fatigue (difference $=+5.4, p=0.021$ ) and nausea/vomiting (difference $+4.4, p=0.032$ ). Regarding the QLQ-BR23, a statistically significant worsening was observed in body image perception (difference $=-5.9$, $p=0.019$ ) and in some systemic therapy side effects (difference $=+6.2, p<0.001$ ) among 7 items.

As expected, a statistically significant decrease of physical, role functioning, and worsening in global health status was observed at the end of treatment (Supplementary Table 4), associated with a worsening of symptoms (fatigue, dyspnea and constipation).

\section{Genotyping results}

Fifteen SPNs were selected based on their reported association with neurotoxicity of several anticancer agents $(14,16,19-25)$. Supplementary Table 5 reports the frequency of variants of all the 15 SNPs and 
the prevalence of each polymorphism was compared with the expected prevalence in Europe. In most cases, concordance was found between the observed prevalence and the expected one.

Among the 15 SNPs, for rs2233335 (in NDRG1 gene; p-value fisher test <0.001) and rs7214723 (in CAMKK1 gene; $\mathrm{p}$-value fisher test $=0.034$ ) a statistically significant association with neuropathy was detected. For the polymorphisms rs7001034 (in FZD3 gene) and rs242557 (in MAPT gene) a higher grade of neurotoxicity was observed in presence of the allele $A$ ( $p$-value $X^{2}$ for trend $=0.012$ and 0.044 for RS7001034 and rs242557, respectively).

To understand the allele responsible for the higher-grade neurotoxicity, the recessive and dominant model were explored. The genotype T/T of the polymorphism rs2233335 (T/T vs. G/G-G/T, $p<0.001$ for both fisher and $X^{2}$ for trend) and the genotype $T / T$ of the polymorphism rs7214723 ( $T / T$ vs. $C / C-C / T, p=0.008$ and $p=0.026$ for fisher and $X^{2}$ for trend, respectively) were associated with a higher grade of neurotoxicity $(p<0.001)$. Considering the neurotoxicity as severe (grade>1) and not-severe (grade $0-1)$ the genotype T/T

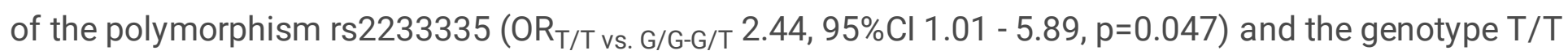
of the polymorphism rs7214723 ( $\left.\mathrm{OR}_{\mathrm{T} / \mathrm{T} \text { vs. } \mathrm{G} / \mathrm{G}-\mathrm{G} / \mathrm{T}} 2.56,95 \% \mathrm{Cl} 1.05-6.27, \mathrm{p}=0.039\right)$ confirmed their association with a higher risk of neurotoxicity (Table 3). The allelic variant $\mathrm{G}$ of the polymorphism rs242557 was associated with a statically significant decrease of the severe neurotoxicity occurrence $\left(\mathrm{OR}_{\mathrm{G} / \mathrm{G} \text { vs. A/G vs. A/A }} 0.47,95 \% \mathrm{Cl} 0.23-0.97, \mathrm{p}=0.042\right)$. For rs7001034 in the $F Z D 3$ gene, no statistically significant association was detected $\left(\mathrm{OR}_{\mathrm{G} / \mathrm{G} \text { vs. } A / G \text { vs. } A / A} 0.60,95 \% \mathrm{Cl} 0.32-1.15, \mathrm{p}=0.122\right)$. 
Table 3. Relationship using dominant or recessive model between polymorphism and neuropathy

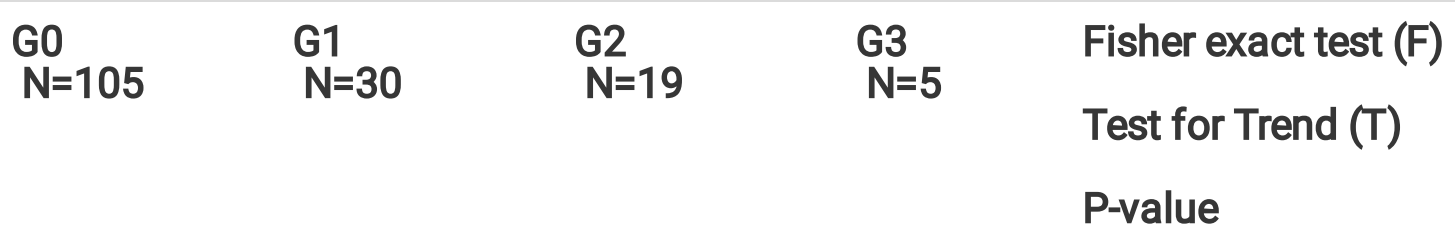

rs2233335 - NDRG1 - model1 - n (\%)

$\begin{array}{llllll}\mathrm{G} / \mathrm{G} \text { or } \mathrm{G} / \mathrm{T} & 79(77.5) & 12(11.8) & 7(6.9) & 4(3.9) & \mathrm{F}:<0.001 \\ \mathrm{~T} / \mathrm{T} & 26(45.6) & 18(31.6) & 12(21.1) & 1(1.8) & \mathrm{T}:<0.001\end{array}$

rs2233335 - NDRG1 - model2 - n (\%)

$\begin{array}{llllll}\text { G/G } & 25(78.1) & 2(6.3) & 3(9.4) & 2(6.3) & \text { F: } 0.088 \\ \text { T/T or G/T } & 80(63.0) & 28(22.0) & 16(12.6) & 3(2.4) & \text { T: } 0.210\end{array}$

rs7214723 - CAMKK1 - model1 - n (\%)

\begin{tabular}{llllll}
$\mathrm{C} / \mathrm{C}$ or $\mathrm{C} / \mathrm{T}$ & $80(70.8)$ & $20(17.7)$ & $8(7.1)$ & $5(4.4)$ & $\mathrm{F}: 0.008$ \\
\hline $\mathrm{T} / \mathrm{T}$ & $23(52.3)$ & $10(22.7)$ & $11(25.0)$ & $0(0.0)$ & $\mathrm{T}: 0.026$ \\
\hline Missing & 2 & 0 & 0 & 0 & \\
\hline
\end{tabular}

rs7214723 - CAMKK1 - model2 - n (\%)

\begin{tabular}{llllll}
$\mathrm{C} / \mathrm{C}$ & $32(68.1)$ & $8(17.0)$ & $5(10.6)$ & $2(4.3)$ & $\mathrm{F}: 0.892$ \\
\hline $\mathrm{T} / \mathrm{T}$ or $\mathrm{C} / \mathrm{T}$ & $71(64.5)$ & $22(20.0)$ & $14(12.7)$ & $3(2.7)$ & T: 0.729 \\
\hline Missing & 2 & 0 & 0 & 0 &
\end{tabular}

Legend: N: Number of subjects. G: Grade.

\section{Discussion}

Treatment of $\mathrm{MBC}$ is a challenge in oncology and for several years no advances in overall survival has been observed [26]. New targeted therapies available in Her-2 positive and Luminal disease are changing the natural history of MBC and new goals have been achieved [3, 27, 28]. Among chemotherapy, which remains a backbone in this setting, eribulin has demonstrated an improvement in OS in patients with Her2-negative MBC after anthracycline/taxane chemotherapy [10]. As stated in the International Consensus Conference on advanced breast cancer, preserving QoL and avoiding treatment related adverse events are important issues for patients with $\mathrm{MBC}$, because it is a chronic and lethal disease [2]. Eribulin represents a new therapeutic option of MBC and as its clinical use will increase in time, a better knowledge of its safety profile outside clinical trials is warranted. Several retrospective studies have been published on the safety of eribulin in real life settings [29-31]; however, few prospective studies, aimed at a proper and complete evaluation of its safety and efficacy in the daily clinical setting are available [32, 
33]. The PAINTER study was planned to investigate the tolerability of eribulin treatment in real life setting and to study the association between neurotoxicity onset and specific gene polymorphisms. The trial enrolled pretreated MBC patients with characteristics typical of this population: mean age 59 years old, 5 median lines of previous chemotherapy for the metastatic setting, up to 18 cycles, and mainly Luminal B Her2-negative (65\%). In the PAINTER study, women received a median of 4,5 cycles of eribulin (range 123), and this data is slightly higher than those reported in the EMBRACE and in the TROTTER study, where patients received 4 lines (range 1-7) and 3 lines (1-10), respectively.

Regarding efficacy, the median OS was 12 months (Q1-Q3: 6.4-21.7 months), in some way similar to other studies: in EMBRACE the median OS was 13.1 months (95\% $\mathrm{Cl} 11.8-14.3)$ and in the pooled analysis of the 2 phase III studies, median OS in the ITT population was 15.2 months (12). Painter OS data are in line with those observed in real life studies: OS of 10.1 months (95\% Cl: 8.1-13), 11.6 months (0.6-33.3 months; $95 \% \mathrm{Cl} 8.7-14.5)$ and 13.53 months (95\% Cl9.39-17.67 months) (29-31). Interestingly in the VESPRY study, median OS was 31.8 months (CI 95\% 27.9-34.4) and as the authors reported, compared with both these pivotal trials (29-31), the OS was prolonged almost 2.5 fold; this clinical benefit can be partially explained by the fact that the patients who received eribulin were not previously heavily pretreated, as all patients were in third line of treatment (34). Also, Gamucci et al, who reported a median OS of 14.3 months $(95 \% \mathrm{Cl}, 11.7-16.8)$ pointed out that significant improvement in response was observed when eribulin is given as third-line $(p=0.02)(35)$.

Our study confirms that, although in a heavy pretreatment setting, eribulin is well tolerated in fact only $3.5 \%$ of pts discontinued treatment for toxicities/severe adverse events. Most adverse events occur within the $6^{\text {th }}$ cycle; in fact, the risk of interrupting or reducing the dose of eribulin is higher in the first cycles than in subsequent ones. This is why some patients could continue the treatment for a very long time, up to 23 cycles. Among other G1-G4 toxicities, of note is the pain, especially osteo-muscular, abdominal and in tumor site observed in $20 \%$ of patients. While this side effect has been described after treatment with other drugs (36), it was never reported after eribulin treatment.

Most of the enrolled patients had been pre-treated with taxanes (97\%), well known neurotoxic drugs, similarly to other studies [10; 35]. Interestingly, in our study, $15 \%$ of patients reported a neurotoxicity before starting eribulin, related to previous treatments; this data is often unreported, but it is very important and must be considered when a patient is proposed to receive eribulin.

About severe toxicity, 38.2\% patients experienced at least one severe adverse event; in particular neutropenia in $15.3 \%$, neurotoxicity in $14.7 \%$ and asthenia in $5.9 \%$. In our opinion, neuropathy is probably under-reported in other studies $(31,33)$; while in the PAINTER study the neurotoxicity incidence was accurately reported due to the way in which we have collected the information. In fact, a specific question on the most frequent toxicities was requested at each cycle in the protocol, including neurotoxicity. Another possible explanation regards the characteristics the population study, such as the starting dose of eribulin, history of radiotherapy, and hemoglobin level at baseline, as identified by Tsurutani et al. as significantly associated with peripheral neuropathy (37). Anyway, it is clear that eribulin causes 
peripheral neuropathy; Zhao et al. demonstrated that eribulin-treated subjects (both with breast cancer and liposarcoma) had a significantly increased risk of all-grade (RR, 2.00;95\% Cl, 1.70-2.35; $\mathrm{p}=0.008)$ and high-grade (RR, $3.68 ; 95 \% \mathrm{Cl}, 2.30-5.89 ; \mathrm{p}<0.001)$ neurotoxicity (38).

A part of PAINTER study was dedicated to explore the role of polymorphisms and their relationship with neuropathy. Fifteen SNPs were analyzed and 2 polymorphisms, rs2233335 (T/T) in NDRG1 gene and rs7214723 (T/T) in CAMKK1 gene, were associated with eribulin-induced severe neurotoxicity. For rs7001034 in FZD3 gene and rs242557 in MAPT gene, an association with neurotoxicity was observed, in particular allele $A$ increases neuropathy occurrence, but it was not confirmed for severe neuropathy. The functions of the involved genes are different; NDRG1 ( $\mathrm{N}$-myc downstream regulated gene-1) is a stress response protein involved in multiple cellular pathways, including the endoplasmic reticulum stress response; CAMKK1 (calcium/calmodulin-dependent protein kinase kinase-1) is a serine/threonine kinase that is activated by increases in intracellular $\mathrm{Ca} 2+$ levels and $\mathrm{Ca} 2+$ /calmodulin binding; FZD3 is a member of the frizzled gene family, that has been shown to play a role in neurite outgrowth and nerve development; finally, MAPT (microtubule associated protein Tau) is involved in tubulin assembly and polymerization. (39-42). The different mechanisms that underlie the neuropathy onset are unknown and many studies are exploring it, also in new drugs, like nab-paclitaxel compared with paclitaxel, suggesting that the selection of the nab-paclitaxel regimen should be individualized based on the clinical context and potentially supported by pharmacogenetic analysis (43).

After three cycles of eribulin, QoL questionnaires showed that global health status was overall preserved, both with social, physical and emotional roles. Patients reported a worsening of fatigue and nausea induced by treatment, while no differences were found in the other 7 symptoms and items investigated. In a metastatic setting, the preservation of a good quality of life is essential and our data show that eribulin treatment allows patients to keep a good health status. The global worsening of health status and symptoms at the end of treatment evaluation, was indeed observed at disease progression.

\section{Conclusion}

The PAINTER study offers a wide spectrum of information about eribulin tolerability. In fact, the prospective nature of the study allowed the investigators to collect many items based on previous studies. As expected, fatigue, peripheral neuropathy and neutropenia were the most common toxicities, but few patients experienced severe AEs. Toxicity rarely led to drug discontinuation, even if schedule and dosage modifications were common, as frequently observed in heavily pretreated pts. Patients' reported outcomes show the preservation of a global health status during the first three cycles of eribulin and a progressive worsening of symptoms at the end of treatment. To the best of our knowledge, this is the first study that demonstrates a correlation between SNPs and neuropathy in eribulin treated patients. Studies are ongoing to understand the molecular mechanisms at the basis of this association. These data, if corroborated in other studies, will allow a tailored treatment with eribulin, addressing a proper use of the drug and avoiding useless toxicity. 


\section{Abbreviations}

AEs adverse events

SAEs severe AE

DOT Duration of treatment

G Grade

MBC Metastatic breast cancer

OR odds ratio

OS overall survival

PN peripheral neuropathy

pts patients

QoL quality of life

SNPs Single Nucleotide Polymorphisms

TPC treatment of physician's choice

\section{Declarations}

\section{Ethics approval and consent to participate}

The study was approved in the center of the principal investigator at Fatebenefratelli Hospital in Milan, Italy. The Ethical Committee was "Comitato Etico Milano Area B". The approval was obtained on December10th, 2013. Every patient signed a written informed consent previously approved by ethical committee

Consent for publication Not applicable

Availability of data and material - The datasets used and/or analyzed during the current study are available from the corresponding author on reasonable request.

\section{Competing interests:}

NLV Eisai, MSD, Roche, Novartis, Astrazeneca, GSK, Pfizer, Gentili, Celgene

GD no competing interests 
OG Eisai, MSD, Pierre Fabre, Seagen, Gilead, Novartis

DS Astrazeneca, Novartis, LILT, University of Trieste, Lilly, Pfizer, Roche, Istituto Gentili

AF Astrazeneca, Celgene, Dompè, Eisai, Lilly, Novartis, Pfizer, Roche, Pierre, Fabre

MC no competing interests

DGG Astrazeneca, Novartis, LILT, University of Trieste, Lilly, Pfizer, Roche, Novartis, Istituto Gentili

MN no competing interests

EP no competing interests

EF no competing interests

EC no competing interests

GS no competing interests

IM Eli Lilly, Novartis, Istituto Gentili, Roche, Pfizer, Ipsen, and Pierre Fabre.

ASB no competing interests

LC Astrazeneca, Pfizer, Ipsen, Celgene

EC no competing interests

ER no competing interests

ER no competing interests

LL no competing interests

FG no competing interests

AB Astellas, Jansenn, GSK

AM Sophosbiotech, Janssen

AC Novartis

PV Eisai, Roche, Pfizer, Novartis, Istituto Gentili

VT no competing interests

GF no competing interests 
Funding - This study was supported by Eisai s.r.l. Italy for biological and statistical analysis

\section{Authors' contributions}

NLV, GD, VT, GF design of the work

GD, FG molecular analysis

ER, LL, VT data acquisition, data analysis

GD, NLV, GF, ER: interpretation of data

AM, FG, NLV, ER: manuscript writer

OG, LD, AF, MC, DG, MN, EP, PP, EC, GS, IM, ASB, LC, EC, ER, GF, AM, AB: patients' enrollment

\section{Acknowledgements}

Istituto di Ricerche Farmacologiche Mario Negri IRCCS, Milano:

Poli Davide, Giuliano Veronica, Montanari Mauro, Rulli Erica

\section{References}

1. Li Z, Kang Y: Emerging therapeutic targets in metastatic progression: A focus on breast cancer. Pharmacol Ther 2016, 161:79-96.

2. Cardoso F, Costa A, Senkus E, Aapro M, Andre F, Barrios CH, Bergh J, Bhattacharyya G, Biganzoli L, Cardoso MJ et al: 3rd ESO-ESMO International Consensus Guidelines for Advanced Breast Cancer (ABC 3). Ann Oncol 2017, 28(1):16-33.

3. Swain SM, Kim SB, Cortés J, et al. Pertuzumab, trastuzumab, and docetaxel for HER2-positive metastatic breast cancer (CLEOPATRA study): overall survival results from a randomised, doubleblind, placebo-controlled, phase 3 study. Lancet Oncol. 2013;14(6):461-471. doi:10.1016/S14702045(13)70130-X

4. Tripathy D, Im SA, Colleoni M, et al. Ribociclib plus endocrine therapy for premenopausal women with hormone-receptor-positive, advanced breast cancer (MONALEESA-7): a randomised phase 3 trial. Lancet Oncol. 2018;19(7):904-915.

5. O'Shaughnessy J, Kaklamani V, Kalinsky K: Perspectives on the mechanism of action and clinical application of eribulin for metastatic breast cancer. Future Oncol 2019, 15(14):1641-1653.

6. Jordan MA, Kamath K, Manna T, Okouneva T, Miller HP, Davis C, Littlefield BA, Wilson L: The primary antimitotic mechanism of action of the synthetic halichondrin E7389 is suppression of microtubule growth. Mol Cancer Ther 2005, 4(7):1086-1095. 
7. Okouneva T, Azarenko O, Wilson L, Littlefield BA, Jordan MA: Inhibition of centromere dynamics by eribulin (E7389) during mitotic metaphase. Mol Cancer Ther 2008, 7(7):2003-2011.

8. Smith JA, Wilson L, Azarenko O, Zhu X, Lewis BM, Littlefield BA, Jordan MA: Eribulin binds at microtubule ends to a single site on tubulin to suppress dynamic instability. Biochemistry 2010, 49(6):1331-1337.

9. Cortes J, Schoffski P, Littlefield BA: Multiple modes of action of eribulin mesylate: Emerging data and clinical implications. Cancer Treat Rev 2018, 70:190-198.

10. Cortes J, O'Shaughnessy J, Loesch D, Blum JL, Vahdat LT, Petrakova K, Chollet P, Manikas A, Dieras $\mathrm{V}$, Delozier $\mathrm{T}$ et al: Eribulin monotherapy versus treatment of physician's choice in patients with metastatic breast cancer (EMBRACE): a phase 3 open-label randomised study. Lancet 2011, 377(9769):914-923.

11. Kaufman PA, Awada A, Twelves C, Yelle L, Perez EA, Velikova G, Olivo MS, He Y, Dutcus CE, Cortes J: Phase III open-label randomized study of eribulin mesylate versus capecitabine in patients with locally advanced or metastatic breast cancer previously treated with an anthracycline and a taxane. J Clin Oncol 2015, 33(6):594-601.

12. Twelves C, Cortes J, Vahdat L, Olivo M, He Y, Kaufman PA, Awada A. Efficacy of eribulin in women with metastatic breast cancer: a pooled analysis of two phase 3 studies. Breast Cancer Res Treat. 2014 Dec;148(3):553-61. Erratum in: Breast Cancer Res Treat. 2015 Jan;149(1):313.

13. Peng L, Hong Y, Ye X, Shi P, Zhang J, Wang Y, Zhao Q: Incidence and relative risk of peripheral neuropathy in cancer patients treated with eribulin: a meta-analysis. Oncotarget 2017, 8(67):112076112084.

14. Cavaletti G, Alberti P, Marmiroli P: Chemotherapy-induced peripheral neurotoxicity in the era of pharmacogenomics. Lancet Oncol 2011, 12(12):1151-1161.

15. Islam B, Lustberg M, Staff NP, Kolb N, Alberti P, Argyriou AA: Vinca alkaloids, thalidomide and eribulininduced peripheral neurotoxicity: From pathogenesis to treatment. J Peripher Nerv Syst 2019, 24 Suppl 2:S63-S73.

16. Frederiks GN, Lam SW, Guchelaar HJ, Boven E. GENETIC POLYMORPHISMS AND PACLITAXEL- OR DOCETAXEL-INDUCED TOXICITIES. A SYSTEMATIC REVIEW. Cancer Treatment Reviews 41 (2015) 935-950

17. C. J. Clopper and E. S. Pearson, The use of confidence or fiducial limits illustrated in the case of the binomial, Biometrika, 26 (1934), 404-413.

18. Machin D Campbell MJ PROGNOSTIC FACTORS STUDIES, IN DESIGN OF STUDIES FOR MEDICAL RESEARCH, John Wiley \& Sons 2005: 227-245

19. Swain SM, ArezZo JC. NEUROPATHY ASSOCIATED WITH MICROTUBULE INHIBITORS: DIAGNOSIS, INCIDENCE, AND MANAGEMENT. Clin Adv Hematol Oncol. 2008;6(6):455-67.

20. Baldwin RM, Owzar K, Zembutsu H, Chhibber A, Kubo M, Jiang C, Watson D, Eclov RJ, Mefford J, McLeod HL, Friedman PN, Hudis CA, Winer EP, Jorgenson EM, Witte JS, Shulman LN, Nakamura Y, Ratain MJ, Kroetz DL. A GENOME-WIDE ASSOCIATION STUDY IDENTIFIES NOVEL LOCI FOR 
PACLITAXEL-INDUCED SENSORY PERIPHERAL NEUROPATHY IN CALGB 40101. Clin Cancer Res. 2012 Sep 15;18(18):5099-109.

21. Sucheston LE, Zhao H, Yao S, Zirpoli G, Liu S, Barlow WE, Moore HC, Thomas Budd G, Hershman DL, Davis W, Ciupak GL, Stewart JA, Isaacs C, Hobday TJ, Salim M, Hortobagyi GN, Gralow JR, Livingston RB, Albain KS, Hayes DF, Ambrosone CB GENETIC PREDICTORS OF TAXANE-INDUCED NEUROTOXICITY IN A SWOG PHASE III INTERGROUP ADJUVANT BREAST CANCER TREATMENT TRIAL (S0221). Breast Cancer Res Treat. 2011 Dec;130(3):993-1002.

22. Mir O, Alexandre J, Tran A, Durand IP, Pons G, Treluyer MJ, Goldwasser F. RELATIONSHIP BETWEEN GSTP1 ILE(105)VAL POLYMORPHISM AND DOCETAXEL-INDUCED PERIPHERAL NEUROPATHY: CLINICAL EVIDENCE OF A ROLE OF OXIDATIVE STRESS IN TAXANE TOXICITY. Ann Oncol. 2009 ;20(4):736-40

23. Sissung TM, Mross K, Steinberg SM, Behringer D, Figg WD, Sparreboom A, Mielke S. ASSOCIATION OF ABCB1 GENOTYPES WITH PACLITAXEL-MEDIATED PERIPHERAL NEUROPATHY AND NEUTROPENIA. Eur J Cancer. 2006 Nov;42(17):2893-6.

24. Hasmats J, Kupershmidt I, Rodríguez-Antona C, Su QJ, Khan MS, Jara C, Mielgo X, Lundeberg J, Green H. IDENTIFICATION OF CANDIDATE SNPS FOR DRUG INDUCED TOXICITY FROM DIFFERENTIALLY EXPRESSED GENES IN ASSOCIATED TISSUES. Gene. 2012 Sep 10;506(1):62-8.

25. Johnson DC, Corthals SL, Walker BA, Ross FM, Gregory WM, Dickens NJ, Lokhorst HM, Goldschmidt H, Davies FE, Durie BG, Van Ness B, Child JA, Sonneveld P, Morgan GJ GENETIC FACTORS UNDERLYING THE RISK OF THALIDOMIDE-RELATED NEUROPATHY IN PATIENTS WITH MULTIPLE MYELOMA. J Clin Oncol. 2011 Mar 1;29(7):797-804

26. La Verde N, Collovà E, Blasi L, Pinotti G, Palumbo R, Bonotto M, Garrone O, Brunello A, Rimanti A, Bareggi C, Zaniboni A, Frassoldati A, Foglietta J, Berardi R, Moretti A, Farina G, Porcu L, Barni S. Overall Survival in Metastatic Breast Cancer Patients in the Third Millennium: Results of the COSMO Study. Clin Breast Cancer. 2020 Nov 9:S1526-8209(20)30272-X.

27. Im SA, Lu YS, Bardia A, et al. Overall Survival with Ribociclib plus Endocrine Therapy in Breast Cancer. N Engl J Med. 2019;381(4):307-316

28. Sledge GW Jr, Toi M, Neven P, Sohn J, Inoue K, Pivot X, Burdaeva O, Okera M, Masuda N, Kaufman PA, Koh H, Grischke EM, Conte P, Lu Y, Barriga S, Hurt K, Frenzel M, Johnston S, Llombart-Cussac A. The Effect of Abemaciclib Plus Fulvestrant on Overall Survival in Hormone Receptor-Positive, ERBB2Negative Breast Cancer That Progressed on Endocrine Therapy-MONARCH 2: A Randomized Clinical Trial. JAMA Oncol. 2019 Sep 29;6(1):116-24.

29. Garrone O, Montemurro F, Saggia C, La Verde N, Vandone AM, Airoldi M, De Conciliis E, Donadio M, Lucio F, Polimeni MA et al: Eribulin in pretreated metastatic breast cancer patients: results of the TROTTER trial-a multicenter retrospective study of eribulin in real life. Springerplus 2016, 5:59.

30. Pedersini R, Vassalli L, Claps M, Tulla A, Rodella F, Grisanti S, Amoroso V, Roca E, Simoncini EL, Berruti A: Eribulin in Heavily Pretreated Metastatic Breast Cancer Patients in the Real World: $A$ Retrospective Study. Oncology 2018, 94 Suppl 1:10-15. 
31. Fabi A, Moscetti L, Ciccarese M, Caramanti M, Salesi N, La Verde N, Russillo M, Generali D, Scandurra G, Vari S, Pacetti U, Cognetti F, Giannarelli D. Eribulin in heavily pretreated metastatic breast cancer patients and clinical/biological feature correlations: impact on the practice. Future Oncol. 2015;11(3):431-8.

32. Jacot W, Heudel PE, Fraisse J, Gourgou S, Guiu S, Dalenc F, Pistilli B, Campone M, Levy C, Debled M et al: Real-life activity of eribulin mesylate among metastatic breast cancer patients in the multicenter national observational ESME program. Int J Cancer 2019, 145(12):3359-3369.

33. Perez-Garcia JM, Cortes J. The safety of eribulin for the treatment of metastatic breast cancer. Expert Opin Drug Saf. 2019 May;18(5):347-355.

34. Adamo V, Ricciardi GRR, Giuffrida D, Scandurra G, Russo A, Blasi L, Spadaro P, lacono C, Soto Parra HJ, Savarino A, Ferraú F, Zerilli F, Verderame F, Butera A, Santangelo C, Franchina V, Caruso M. Eribulin mesylate use as third-line therapy in patients with metastatic breast cancer (VESPRY): a prospective, multicentre, observational study. Ther Adv Med Oncol. 2019 Dec 19;11:1758835919895755.

35. Gamucci T, Michelotti A, Pizzuti L, Mentuccia L, Landucci E, Sperduti I, Di Lauro L, Fabi A, Tonini G, Sini V, Salesi N, Ferrarini I, Vaccaro A, Pavese I, Veltri E, Moscetti L, Marchetti P, Vici P. Eribulin mesylate in pretreated breast cancer patients: a multicenter retrospective observational study. $\mathrm{J}$ Cancer. 2014 Mar 20;5(5):320-7.

36. Altinoz MA, Ozpinar A, Alturfan EE, Elmaci I. Vinorelbine's anti-tumor actions may depend on the mitotic apoptosis, autophagy and inflammation: hypotheses with implications for chemoimmunotherapy of advanced cancers and pediatric gliomas. J Chemother. $2018 \mathrm{Jul} ; 30(4): 203-212$. doi: 10.1080/1120009X.2018.1487149. Epub 2018 Jul 20. PMID: 30025492.

37. Tsurutani J, Sakata Y, Matsuoka T. Chemotherapy-induced peripheral neuropathy in breast cancer patients treated with eribulin: interim data from a post-marketing observational study. Breast Cancer. 2019 Mar;26(2):235-243.

38. Zhao B, Zhao H, Zhao J. Incidence and clinical parameters associated with eribulin mesylate-induced peripheral neuropathy. Crit Rev Oncol Hematol. 2018 Aug;128:110-117. doi:

10.1016/j.critrevonc.2018.06.003. Epub 2018 Jun 12. Erratum in: Crit Rev Oncol Hematol. 2019 Mar;135:20.

39. Fukuda Y, Li Y, Segal RA. A Mechanistic Understanding of Axon Degeneration in ChemotherapyInduced Peripheral Neuropathy. Front Neurosci. 2017 Aug 31;11:481.

40. Park SB, Kwok JB, Loy CT, Friedlander ML, Lin CS, Krishnan AV, Lewis CR, Kiernan MC. Paclitaxelinduced neuropathy: potential association of MAPT and GSK3B genotypes. BMC Cancer. 2014 Dec 22; $14: 993$

41. Johnson DC, Corthals SL, Walker BA, Ross FM, Gregory WM, Dickens NJ, Lokhorst HM, Goldschmidt H, Davies FE, Durie BG, Van Ness B, Child JA, Sonneveld P, Morgan GJ. Genetic factors underlying the risk of thalidomide-related neuropathy in patients with multiple myeloma. J Clin Oncol. $2011 \mathrm{Mar}$ 1;29(7):797-804. 
42. Sundar R, Jeyasekharan AD, Pang B, Soong RC, Kumarakulasinghe NB, Ow SG, Ho J, Lim JS, Tan DS, Wilder-Smith EP, Bandla A, Tan SS, Asuncion BR, Fazreen Z, Hoppe MM, Putti TC, Poh LM, Goh BC, Lee SC. Low Levels of NDRG1 in Nerve Tissue Are Predictive of Severe Paclitaxel-Induced Neuropathy. PLoS One. 2016 Oct 7;11(10):e0164319.

43. Ciruelos E, Apellániz-Ruiz M, Cantos B, Martinez-Jáñez N, Bueno-Muiño C, Echarri MJ, Enrech S, Guerra JA, Manso L, Pascual T, Dominguez C, Gonzalo JF, Sanz JL, Rodriguez-Antona C, Sepúlveda JM. A Pilot, Phase II, Randomized, Open-Label Clinical Trial Comparing the Neurotoxicity of Three Dose Regimens of Nab-Paclitaxel to That of Solvent-Based Paclitaxel as the First-Line Treatment for Patients with Human Epidermal Growth Factor Receptor Type 2-Negative Metastatic Breast Cancer. Oncologist. 2019 Nov;24(11):e1024-e1033.

\section{Figures}

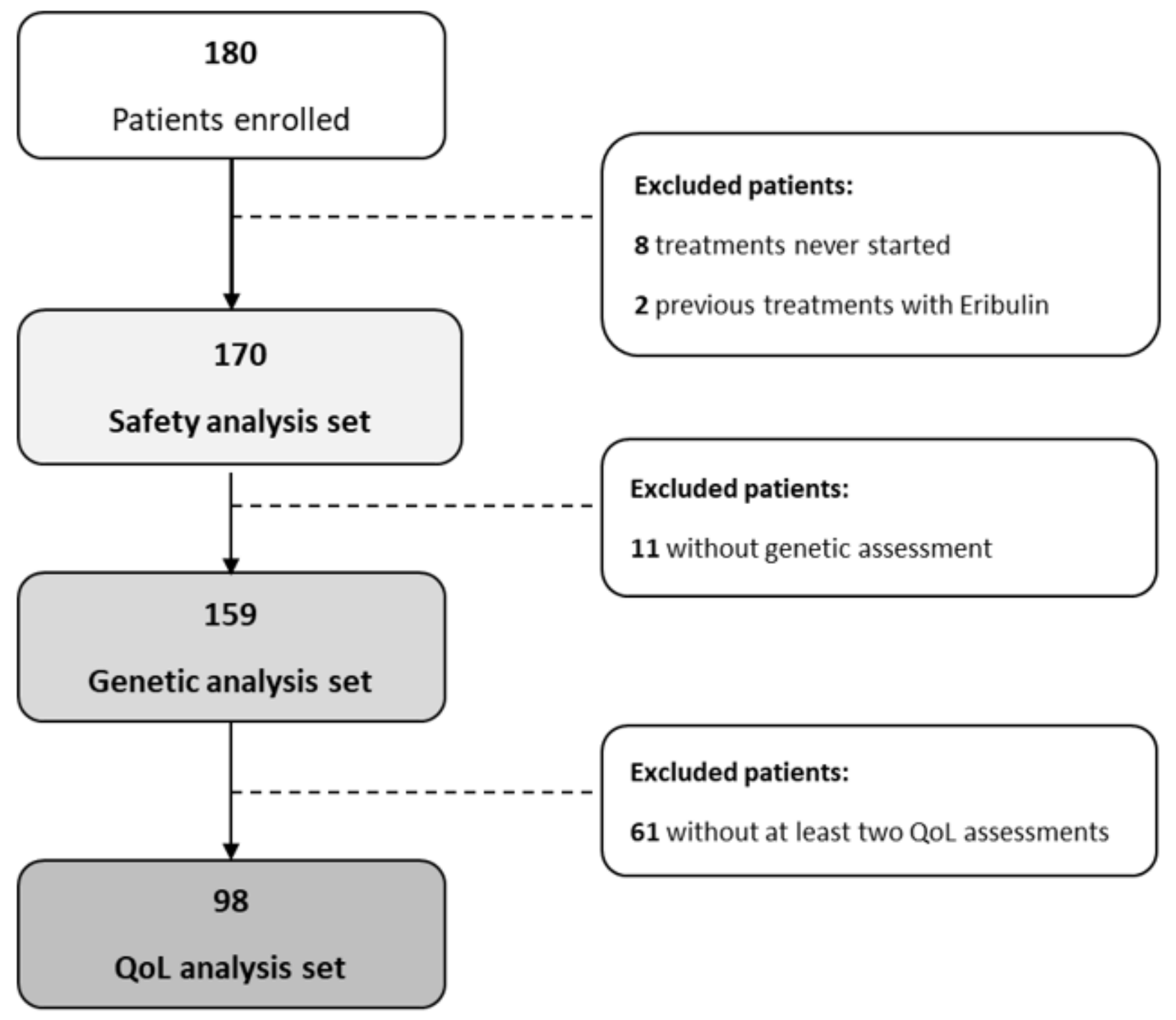

Figure 1 

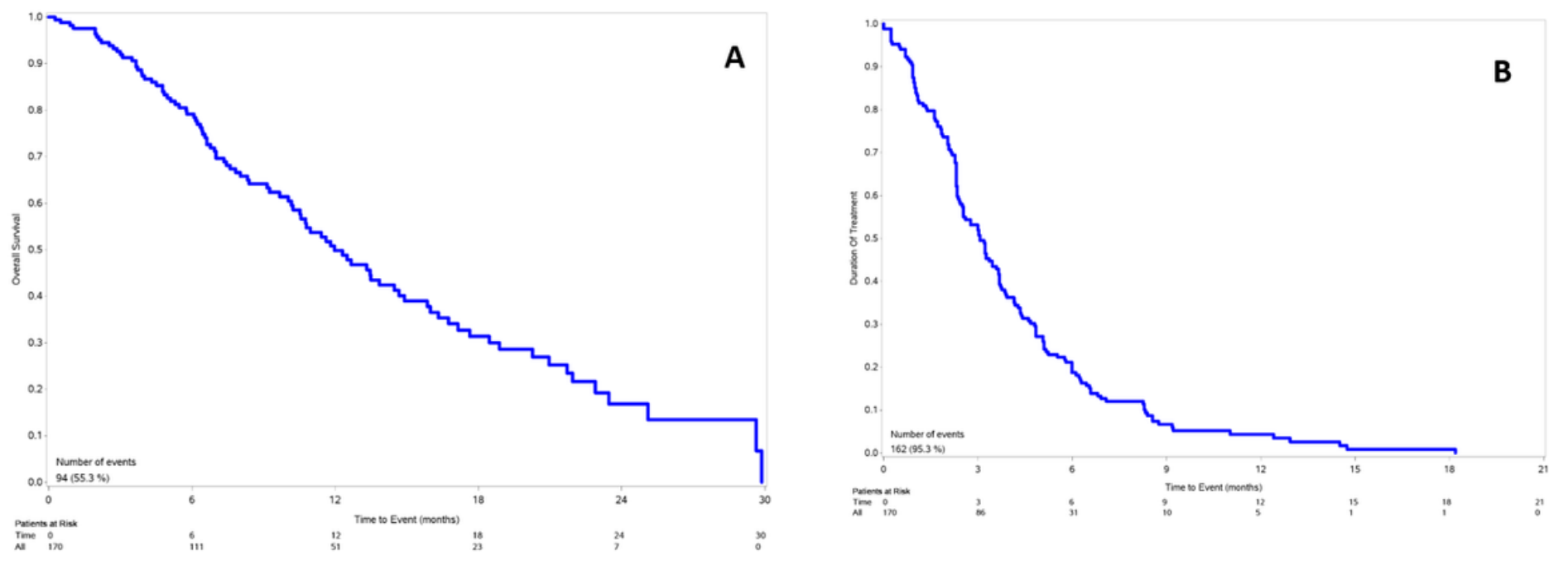

Figure 2

A Overall survival; B Duration of treatment
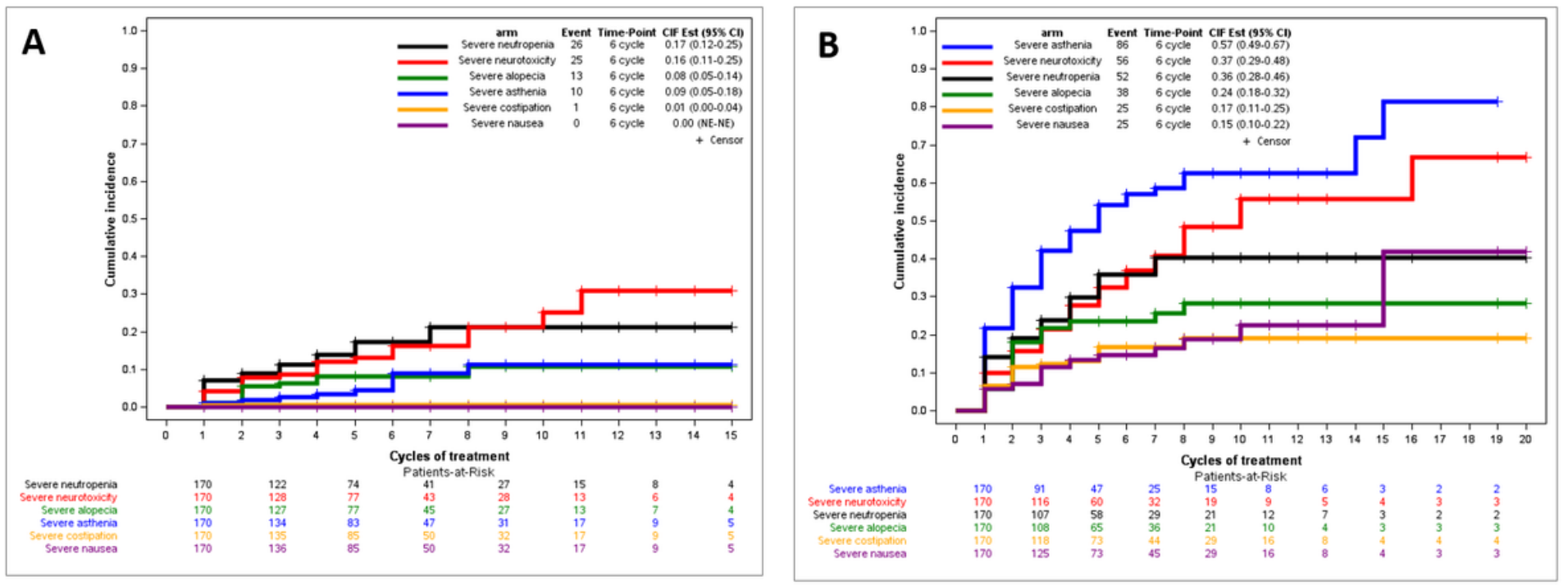

Figure 3

Cumulative incidence of severe toxicities (A) and any grade toxicity (B) 


\section{Supplementary Files}

This is a list of supplementary files associated with this preprint. Click to download.

- supplementarytables.docx 